\title{
Grand challenges and opportunities for molecular psychiatry research: a perspective
}

\author{
Ming D. Li* \\ Department of Psychiatry and Neurobehavioral Sciences, University of Virginia, Charlottesville, VA, USA \\ *Correspondence: Ming_Li@virginia.edu
}

Molecular psychiatry is a still nascent field, aspiring to imitate the great development of revolutionary tools and techniques achieved elsewhere. The rapid development of new methods such as high-throughput genomic and bioinformatics technologies has greatly advance our understanding of the pathology and etiology of most, if not all, psychiatric disorders, far beyond what we would have expected a few years ago.

Although these great advances have brought us closer to understanding the development of many psychiatric disorders, the majority of the questions about their origins remain. Many of these questions are not only of great scientific importance but also of broad interest to the rest of society and the general public. As reported recently by the World Health Organization (2008), disorders of the nervous system affect hundreds of millions of people worldwide. For example, depression affects 154 million people, 25 million people suffer from schizophrenia, 91 million people are affected by alcohol use disorders, 15 million people suffer from drug use disorders, epilepsy impacts 50 million, and 24 million people suffer from Alzheimer's disease or other dementias. The collective burden of these disorders has a significant impact on the world's economic output.

The primary missions of research in molecular psychiatry are, first, to understand the mechanisms underlying the development of these psychiatric disorders at the molecular level and then to find ways to prevent and treat them more effectively. Such broad missions determine that molecular psychiatry is not a single science but rather a multidisciplinary enterprise including diverse fields such as molecular biology and genetics, psychology and psychiatry, neurology, pharmacology, chemistry, biostatistics and bioinformatics, and engineering and computer sciences. Our past successes - in combination with the revolutionary new tools and technologies from molecular biology and genetics, information science and technology, mathematics, bioinformatics, and neuroimaging - have positioned molecular psychiatry on the cusp of even greater transformational progress in our understanding of the brain and how its actions result in mental activities and various disorders of the nervous system.

For decades, philosophers and scientists have argued about the influences of nurture (or biological inheritance) versus nature. As our understanding of the brain has advanced, it has become clear that what really matters is the interplay between nature and nurture. To the best of our knowledge, almost all common psychiatric disorders such as schizophrenia, bipolar disorder, Alzheimer's disease, and addiction are complex genetic disorders influenced by both biologic and environmental factors as well as their interactions. There is no doubt that the fields of psychiatry and other nervous system disorders have benefited tremendously from better understanding of the role of genetics. However, genes do not equate with destiny. Not only does the environment impact the development of these complex psychiatric disorders, but genetics as well. With an improved understanding of brain functions; i.e., the brain's ability to shape, form, eliminate, and strengthen different neuronal networks and circuitries, we can begin to understand how brain structure and function continue to change throughout our lives. What we do in brain research, more specifically in molecular psychiatry, is to determine which genes and variants are involved and how they are expressed over different developmental stages or interact with environmental factors to shape each person's life. To attack these daunting but important tasks, there exist many challenges, which can be summarized briefly as follows.

The first challenge is to determine which genes and, specifically, which variants contribute to the development of a psychiatric disorder. Although this effort with either candidate gene-based or a genome-wide association (GWA) study has continued for years and has identified numerous genes for each disorder, only a few of them have been replicated in independent samples, in which small sample size (especially for earlier studies) and heterogeneity in defining each phenotype and outcome measure might have contributed greatly to this problem. To address those concerns, we must increase our sample size through pooled approach or meta-analysis of multiple independent samples reduce potential heterogeneity among the samples by using intermediate phenotypes such as endophenotypes, heritable biochemical or neurophysiological markers (i.e., determined by genes), and objective measures (i.e., less influenced by behavioral factors or biased by each investigator). On the other hand, we need to realize that sample size can only change the final $P$-value for our results from the association test and has no impact on the effect size of each genetic variant under investigation. In other words, we should not be fooled by final $P$ values and must have a proper balance between sample size (power) and the cost of subject recruitment, genotyping, and statistical analysis. Although we all agree that GWA has been relatively successful in finding genetic variants responsible for a psychiatric disease, with the identification of variants in the nicotinic receptor subunit genes cluster on chromosome 15 that are important for smoking dependence and lung cancer being one of the most successful examples (e.g., Amos et al., 2008; Hung et al., 2008; Thorgeirsson et al., 2008), there exist various limitations of this powerful approach. Because of the concern about false positives that may result from such a high-throughout approach, a stringent threshold for genome-wide significance level must be adopted, in which only a few genetic markers can survive correction for multiple testing, a number that appears to be far less than we would expect according 
to quantitative genetics theory for complex traits determined by many factors, each with a small effect size. As markers identified by GWA studies can explain only a small proportion (less than $5 \%$ in most cases) of the phenotypic variance observed (Visscher and Montgomery, 2009), the hypothesis that common complex diseases are attributable to a relatively few common genetic variants has been questioned (Manolio et al., 2009).

The second challenge is to identify the functional variant(s) that causes the observed association with a disease and the molecular mechanism by which it exerts its effects. So far, most variants identified through either candidate genebased or GWA studies are not causative: The reason for their association with the phenotype is linkage disequilibrium with functional variants. This may also be one of the primary reasons for many reported associations that cannot be replicated. Deep sequencing of previously identified genes associated with a disease thus represents a logical step for identifying those rare variants, especially with those family samples recruited for genetic studies on a specific psychiatric disease of interest. For example, four rare genetic variants in a candidate gene for type 1 diabetes at approximately $1 \%$ frequency were identified through resequencing that in total contributed more to variation in the population than a single common variant in the same gene detected by a previous GWA study (Nejentsev et al., 2009). Although samples may be limited, all genetic variations (including rare SNPs, copy number of variations, insertions and deletions) identified through the ongoing 1000 Genome Project (www.1000genomes. org) can serve as a useful resource for this effort. In addition to identifying functional and rare genetic variants, it is necessary to determine how they contribute to the development of psychiatric disorders; i.e., their mechanisms of action. This can be accomplished by employing conventional molecular techniques such as allele-specific expression, reporter assays, and imaging analysis, to name a few. Although it is easy to understand how a nonsynonymous variant impacts the function(s) of a protein, it is equally important to concentrate on those variants located in the regulatory regions of both the $5^{\prime}$ and $3^{\prime}$ ends of a gene, as they are more common and related to regulation of expression of a gene through changing binding affinity of transcriptional factors or microRNAs, a relatively new class of small non-coding RNAs implicated in the regulation of gene expression through interaction with the $3^{\prime}$ end of a target RNA (Bartel, 2004). For example, one recent study revealed that differential allelic expression of a functional SNP, rs686, in the 3'-UTR of DRD1 is mediated by miR-504 (Huang and $\mathrm{Li}, 2009$ ).

The third challenge is to understand how epigenetic mechanisms, which regulate gene activity without altering the genetic code, contribute the pathogenesis of diseases. Several processes such as $\mathrm{CpG}$ methylation and histone modification occur throughout a lifetime and are thought to be major factors in many psychiatric illnesses such as depression, drug addiction, and schizophrenia. Changes in histone modifications and DNA methylation have been found both globally and in the promoters of genes implicated in these diseases (Tsankova et al., 2007). Although genome-wide epigenetic approaches have yielded significant findings in developmental and cancer biology, such studies in psychiatric research are relatively lacking.

The fourth challenge is how to utilize the knowledge and information gained from genetic/genomic studies in medicine practice. There are at least two aspects of this challenge. The first is related drug discovery based on validated molecular targets. Given the complexities and high degree of variability in genetic variants, preclinical models to assess drug efficacy, and human trials with appropriate statistical power, we need to develop a system-wide approach to facilitate the translation of basic discoveries into validated drug targets (Conn and Roth, 2008). The second aspect is related to genetic testing and personalized medicine. Although it may be difficult now to implement genetic testing in prevention programs for psychiatric disorders because of ethical concerns and the availability of limited causative variants in genes implicated in a disease, the prospect of using genetics information to tailor medical treatment for psychiatric disorders is exciting.

The final challenge is how to handle the massive datasets and other information collected by those approaches. With the advance of technologies, massive data can be generated quickly from GWA studies, RNA expression studies based on microarray and RNA sequencing, genome-wide studies of changes in methylation and histones, and targeted deep sequencing for both SNPs and CNVs of whole genome or candidate genes implicated in psychiatric illnesses. Unfortunately, only a few research laboratories are staffed and equipped for such challenges in both hardware and software. To face such challenges, we need active collaborations among molecular biologists, biostatisticians, and computer scientists to find effective means/tools, not only to manage the data, but also to analyze and interpret them.

In sum, we have made significant progress toward our goals; however, we still have long way to go. Yes, these are challenges but also opportunities. Much work needs to be done, not only to determine which genetic variants are involved and how they are engaged through what mechanisms but also how to translate these basic science advances into new therapeutic options for the prevention and treatment of psychiatric disorders.

\section{ACKNOWLEDGMENTS}

The preparation of this article was in part supported by NIH grants DA-12844 and DA-13783.

\section{REFERENCES}

Amos, C. I., Wu, X., Broderick, P., Gorlov, I. P., Gu, J., Eisen, T., Dong, Q., Zhang, Q., Gu, X., Vijayakrishnan, J., Sullivan, K., Matakidou, A., Wang, Y., Mills, G., Doheny, K., Tsai, Y. Y., Chen, W. V., Shete, S., Spitz, M. R., and Houlston, R. S. (2008). Genome-wide association scan of tag SNPs identifies a susceptibility locus for lung cancer at 15q25.1. Nat. Genet. 40, 616-622.

Bartel, D. P. (2004). MicroRNAs: genomics, biogenesis, mechanism, and function. Cell 116, 281-297.

Conn, P. J., and Roth, B. L. (2008). Opportunities and challenges of psychiatric drug discovery: roles for scientists in academic, industry, and government settings. Neuropsychopharmacology 33, 2048-2060.

Huang, W., and Li, M. D. (2009). Differential allelic expression of dopamine D1 receptor gene (DRD1) is modulated by microRNA miR-504. Biol. Psychiatry 65, 702-705.

Hung, R. J., McKay, J. D., Gaborieau, V., Boffetta, P. Hashibe, M., Zaridze, D., Mukeria, A., SzeszeniaDabrowska, N., Lissowska, J., Rudnai, P., Fabianova, E., Mates, D., Bencko, V., Foretova, L., Janout, V., Chen, C., Goodman, G., Field, J. K., Liloglou, T., Xinarianos, G., Cassidy, A., McLaughlin, J., Liu, G., Narod, S., Krokan, H. E., Skorpen, F., Elvestad, M. B., Hveem, K., Vatten, L., Linseisen, J., ClavelChapelon, F., Vineis, P., Bueno-de-Mesquita, H. B., Lund, E., Martinez, C., Bingham, S., Rasmuson, T., Hainaut, P., Riboli, E., Ahrens, W., Benhamou, S., Lagiou, P., Trichopoulos, D., Holcatova, I., Merletti, 
F., Kjaerheim, K., Agudo, A., Macfarlane, G., Talamini, R., Simonato, L., Lowry, R., Conway, D. I., Znaor, A., Healy, C., Zelenika, D., Boland, A., Delepine, M., Foglio, M., Lechner, D., Matsuda, F., Blanche, H., Gut, I., Heath, S., Lathrop, M., and Brennan, P. (2008). A susceptibility locus for lung cancer maps to nicotinic acetylcholine receptor subunit genes on $15 \mathrm{q} 25$. Nature 452, 633-637.

Manolio, T. A., Collins, F. S., Cox, N. J., Goldstein, D. B., Hindorff, L. A., Hunter, D. J., McCarthy, M. I., Ramos, E. M., Cardon, L. R., Chakravarti, A., Cho, J. H., Guttmacher, A. E., Kong, A., Kruglyak, L., Mardis, E., Rotimi, C. N., Slatkin, M., Valle, D., Whittemore, A. S., Boehnke, M., Clark, A. G., Eichler, E. E., Gibson, G., Haines, J. L., Mackay, T. F., McCarroll, S. A., and Visscher, P. M. (2009). Finding the missing heritability of complex diseases. Nature 461, 747-753.

Nejentsev, S., Walker, N., Riches, D., Egholm, M., and Todd, J. A. (2009). Rare variants of IFIH1, a gene implicated in antiviral responses, protect against type 1 diabetes. Science 324, 387-389.
Thorgeirsson, T. E., Geller, F., Sulem, P., Rafnar, T., Wiste, A., Magnusson, K. P., Manolescu, A., Thorleifsson, G., Stefansson, H., Ingason, A., Stacey, S. N., Bergthorsson, J. T., Thorlacius, S., Gudmundsson, J., Jonsson, T., Jakobsdottir, M., Saemundsdottir, J., Olafsdottir, O., Gudmundsson, L. J., Bjornsdottir, G., Kristjansson, K., Skuladottir, H., Isaksson, H. J., Gudbjartsson, T., Jones, G. T., Mueller, T., Gottsater, A., Flex, A., Aben, K. K., de Vegt, F., Mulders, P. F., Isla, D., Vidal, M. J., Asin, L., Saez, B., Murillo, L., Blondal, T., Kolbeinsson, H., Stefansson, J.G., Hansdottir, I., Runarsdottir,V., Pola, R., Lindblad, B., van Rij, A. M., Dieplinger, B., Haltmayer, M., Mayordomo, J. I., Kiemeney, L. A., Matthiasson, S. E., Oskarsson, H., Tyrfingsson, T., Gudbjartsson, D. F., Gulcher, J. R., Jonsson, S., Thorsteinsdottir, U., Kong, A., and Stefansson, K. (2008). A variant associated with nicotine dependence, lung cancer and peripheral arterial disease. Nature 452, 638-642.

Tsankova, N., Renthal, W., Kumar, A., and Nestler, E. J. (2007). Epigenetic regulation in psychiatric disorders. Nat. Rev. Neurosci. 8, 355-367.
Visscher, P. M., and Montgomery, G. W. (2009). Genome-wide association studies and human disease: from trickle to flood. JAMA 302, 2028-2029.

WHO. (2008). Intergrating Mental Health into Primary Care: A Global Perspective. Geneva, WHO. www. who.int/mental_health/resources/mentalhealth_ PHC_2008.pdf

Received: 19 August 2009; accepted: 04 January 2010; published online: 18 January 2010.

Citation: Li MD (2010) Grand challenges and opportunities for molecular psychiatry research: a perspective. Front. Psychiatry 1:2. doi: 10.3389/fpsyt.2010.00002

This article was submitted to Frontiers in Molecular Psychiatry a specialty of Frontiers in Psychiatry. Copyright $\odot 2010$ Li. This is an open-access article subject to an exclusive license agreement between the authors and the Frontiers Research Foundation, which permits unrestricted use, distribution, and reproduction in any medium, provided the original authors and source are credited. 